Sitzungsberichte

der Akademie der WVissenschaften

der DDR

Jahrgang $1977 \cdot \mathrm{Nr} .9 / \mathrm{N}$

Mathematik - Naturwissenschaften - Technik

Walter Kirsche

\title{
Christian Gottfried Ehrenberg
}

zum 100. Todestag

Ein Beitrag zur Geschichte

der mikroskopischen Hirnforschung

AKADEMIE-VIERLAG - BERLIN

1977

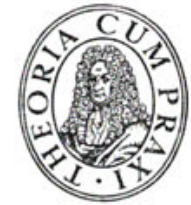


Vortrag von Walter Kirsche

Ordentliches Mitglied der Akademie

der Wissenschaften der DDR auszugsweise

gehalten vor der Klasse Medizin

am 6. Mai 1976

Herausgegeben im Auftrage

des Präsidenten der Akademie

der Wissenschaften der DDR

von Vizepräsident Prof. Dr. Heinrich Scheel

Erschienen im Akademie-Verlag, 108 Berlin, Leipziger Str. 3-4

(C) Akademie-Verlag Berlin

Lizenznummer: $202 \cdot 100 / 254 / 77$

Gesamtherstellung: VEB Druckhaus Köthen

Bestellnummer: $7625403(2010 / 77 / 9 / \mathrm{N}) \cdot$ LSV 1305

Printed in GDR

DDR 6,- M 




Abb. 1 Christian Gottfricd Ehrenberg 1795-1876. Ständiger Sekretär der preußischen Akademie der Wissenschafıen von 1842-1867. Nach einem Gemälde von E. L. Radtke: Christian Goltfricd Ehrenberg (1857). Schlösser und Gärten Potsdam-Sanssouci, Neues Palais. Leinwand $117 \times 86$. 



\section{Inhalt}

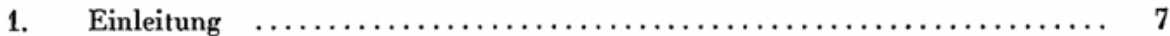

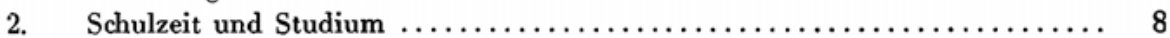

3. Beziehungen zu Alexander von Нuмвоцd - Forschungsreisen $\ldots \ldots \ldots \ldots \ldots$.

4. Naturwissenschaftliche Forschungsergebnisse $\ldots \ldots \ldots \ldots \ldots \ldots \ldots \ldots \ldots \ldots$

5. Berufungen - Beziehungen zur Medizin $\ldots \ldots \ldots \ldots \ldots \ldots \ldots \ldots \ldots \ldots \ldots \ldots \ldots \ldots \ldots \ldots$

6. Ergebnisse zur Histologie und mikroskopischen Anatomie des Nervensystems im Vergleich zu Befunden seiner Vorgänger und Zeitgenossen $\ldots \ldots \ldots \ldots .15$

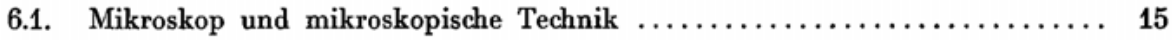

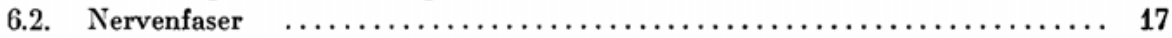





6.3.2. Entdeckung der Nervenzelle durch Ehrenserg $\ldots \ldots \ldots \ldots \ldots \ldots \ldots \ldots \ldots .29$

6.3.3. Arbeiten nach der Entdeckung der Nervenzelle durch Ehrenserg ......... 33

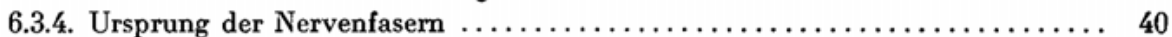

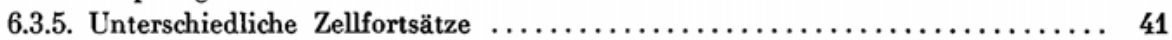



7. Allgemeine Außerungen zur Forschung, Ehrungen, Lebensabend ......... 49



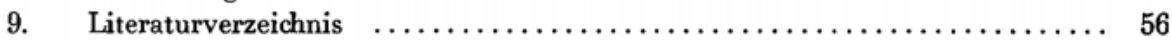


